\title{
A Conversation with Nicholas Proudfoot
}

\author{
INTERVIEWER: RICHARD SEVER \\ Assistant Director, Cold Spring Harbor Laboratory Press
}

Nicholas Proudfoot, FRS, is Brownlee-Abraham Professor of Molecular Biology in the Dunn School at the University of Oxford.

Richard Sever: You've been working on long noncoding RNA. These are not protein-coding, and there are a bunch of classes. Can you remind us what these are?

Dr. Proudfoot: The concept of the gene is that genes make proteins, so the critical genes in mammalian genomes would be protein-coding genes. Obviously, it was appreciated that there were lots of other transcription units that made structural RNAs like ribosomal RNA or tRNA, and these are actually made by different RNA polymerases. But the RNA polymerase II that makes the proteincoding genes also does a lot of other transcription that doesn't seem to be directly related to producing a messenger RNA and then a protein. When mammalian proteincoding genes were first picked apart, it was clear that a large fraction of the gene is actually noncoding; it's intronic. You get extraordinary situations where $90 \%-95 \%$ of the transcription unit is actually intronic and is removed by splicing and then largely degraded.

Then, once genomic or transcriptomic analysis became possible and you could really get a more complete and higher-resolution profile of transcription across the genome, there was the realization that there are a bunch of transcripts that were entirely noncoding. Initially, the simplest interpretation on the discovery of these noncoding RNAs was that if they exist, they must be there for a purpose. The problem is that, in general, these noncoding RNAs are very unstable and they are rapidly degraded, so the cell doesn't usually take a lot of care over producing very much of them.

Richard Sever: These are distinct from the microRNAs?

Dr. Proudfoot: The microRNAs are really fragments of RNA that come out of other transcription units. Most microRNAs actually come out of these large introns in protein-coding genes. We estimate about $70 \%-80 \%$ of microRNAs come out of the introns of protein-coding genes, but there are some noncoding RNAs that also host transcripts to microRNAs.

Richard Sever: These long noncoding RNAs are where? In the introns, in promoter regions, enhancers, between genes?
Dr. Proudfoot: What's apparent about many long noncoding RNAs is that they're almost made by accident by the protein-coding genes. When RNA polymerase II initiates transcription on the promoter, as well as going in the forward direction to make the pre-messenger RNA, it can also go backward to make a long noncoding RNA. Basically, RNA polymerase II is a fairly naive enzyme complex. It'll bind to anywhere that is accessible, which is a nucleosome-free region, and then it'll just go in either direction. The vast majority of protein-coding gene promoters are bidirectional.

Richard Sever: This produces an antisense transcript?

Dr. Proudfoot: It's not antisense, because it initiates outside the transcriptional region of the protein-coding gene, but it goes into the 5'-flanking region. So there's that type of long noncoding RNA.

Also, enhancers can generate transcripts directly themselves. Protein-coding genes are often regulated by a bunch of really distant promoter elements. You can regard enhancers as being separate promoter elements that come together in $3 \mathrm{D}$ by some sort of chromosome looping to form the actual promoter hub. Because these enhancers are regions of open chromatin, RNA polymerase II can also get in there and go in either direction.

Richard Sever: Is that the common feature, that you've got some open chromatin?

Dr. Proudfoot: That's right. Probably in most cell types, the antisense promoter transcripts and the enhancer transcripts will account for well over $50 \%$, if not $75 \%$, of the long noncoding RNAs. Enhancers are very numerous and they're all generating transcripts, usually in both directions.

Richard Sever: Is there such a thing as "junk" RNA, or do these serendipitously generated transcripts actually have a role?

Dr. Proudfoot: Initially, you could regard them as junk, but they are greatly beneficial to evolution. Although they're not used at a particular evolutionary stage, sometimes these transcripts acquire a function that then makes

(C) 2019 Proudfoot. This article is distributed under the terms of the Creative Commons Attribution License, which permits unrestricted reuse and redistribution provided that the original author and source are credited. 
them very valuable for the regulation of gene expression in a cell. A classic example is a long noncoding RNA called NORAD [noncoding RNA activated by DNA damage]. It probably began its life as a nonfunctional transcript, but it happened to have a bunch of binding sites for this very interesting protein called Pumilio. Pumilio is very important in development and, indirectly, with DNA damage and other important issues for cells to cope with. I guess evolution then increased the number of Pumilio binding sites, so it has a whole bunch of them. It ends up being a sponge that regulates the levels of Pumilio in the cell.

There's an analogy to introns. Introns are mainly functionless, but evolution has put some introns to good use. You can get microRNAs out of them, and there are other small RNAs that are chopped out of introns like snoRNAs [small nucleolar RNAs]. Of course, the benefit of having introns - or rather, having genes cut up into exons - is that you can have different combinations of exons to give you different proteins. You get a greatly increased proteome through the presence of introns. Maybe long noncoding RNAs also provide potential evolutionary advantage. You certainly see more long coding RNAs the more complex the eukaryote. You see some long noncoding RNAs in $S$ [accharomyces] cerevisiae, but as you go up into mammals you see a lot more.

There are also some long noncoding RNAs that don't seem to be directly connected to an adjacent proteincoding gene, and these are often referred to as long intergenic noncoding RNAs, the lincRNAs. They're really the same thing as eRNAs [enhancer RNAs] and promoter antisense RNAs in that they probably don't code for any proteins and some of them may or may not have a function. Some of them may just be a patch of chromatin in an intergenic region that becomes open for some unknown reason, and then it becomes, potentially, a promoter.

Richard Sever: When we think of mRNA, there's a specific set of signals in the DNA that is used to initiate transcription. What's happening with these sites?

Dr. Proudfoot: Some of them may have evolved binding sites for transcription initiation factors and may become more like bona fide protein-coding promoters. One trick that we think is important for generating a lot of long noncoding RNAs is that when transcripts are made by any polymerase, one of the things they can do is reanneal back to the DNA template. As the polymerase initiates transcription from a promoter, the first thing it does to the DNA template is to unwind it a bit. Because the DNA is partly underwound, and because the polymerase has to expand the nucleosome-free zone as it transcribes the gene, you have a nascent RNA coming out from behind the polymerase that is just lying in wait to get back in. And, indeed, it does. This RNA-DNA hybrid is called an R-loop. The point about the R-loop is that because you displace one of the DNA strands in the double helix, the single-strand DNA is now prone to damage. R-loops are damage-inducing, so the cell has evolved lots of mechanisms to get rid of these awkward structures. There are lots of helicases that unzip the RNA-DNA hybrids. I suspect that virtually all transcriptions will form these RNA-DNA hybrids a lot of the time. If you look at the steady state profile of R-loops across the genome, you see plenty of them, but they're probably there when the formation has outcompeted their removal.

We knew R-loops were particularly associated with the beginnings of the transcription units and also quite often at the end of the transcription units, where the original nucleosome-free zones tend to be in genes. When you form an R-loop, the displaced DNA strand is actually the exact template you need to initiate transcription. The initiation factors pull apart the DNA strands so that RNA polymerase can get into the template strand and start copying it. The R-loops expose the single-strand DNA straight off by forming the hybrid on the other strand. That's now a potential template for initiation of transcription just by itself. The polymerase will go to any open region of chromatin. It'll greatly prefer to go to a single-strand DNA; that's exactly what it needs to start transcribing. What we've shown is that RNA polymerase does indeed bind to these R-loops and transcribes the strand that was displaced. It's making an antisense transcript to the normal sense transcript, which is the exact orientation of many of these long noncoding RNAs. We showed this happens in vitro. We artificially made a plasmid with an R-loop in the middle of it. We stuck it into a nuclear extract and, lo and behold, you generate a transcript that you can see initiates in the singlestrand region of the R-loop. We've also spent a lot of time trying to prove this happens in vivo and we think we have.

Richard Sever: How do you do that?

Dr. Proudfoot: It's kind of indirect. You have to show that a long noncoding RNA transcript really is dependent on an R-loop. The simplest way to do that is to overexpress this enzyme that gets rid of the RNA-DNA hybrid, RNase H. If you overexpress RNase $H$, you can then show that not only do you get rid of R-loops, you also lose a whole set of these long noncoding RNAs, particularly the ones that come from the backward promoters, but also the enhancers. The enhancer transcripts also form R-loops and you can see that if you overexpress RNase $\mathrm{H}$ a lot of the enhancerderived long noncoding RNAs disappear. I think that quite a high fraction of the noncoding transcriptome might well derive from this type of R-loop promoter activity.

Richard Sever: Presumably, as the mRNA is being synthesized, it can either reanneal or interact with the transcriptional processing proteins. Is there some regulation?

Dr. Proudfoot: There clearly are specific cases where this is likely to be regulated, but we have no direct evidence for the regulated formation of R-loops so that they can initiate transcription in a backward direction. It smells more like a "genome accident." Transcription is dangerous, basically. If you make a transcript, you're exposing the DNA to damage. You're exposing it to the formation of these R-loop structures and you generate all these extra transcripts.

What we've shown in my lab is that many of these long noncoding RNAs initiate from this R-loop promoter 
mechanism, but then the cell has evolved the way to stop them going too far. There's a complex called the "Integrator complex" associated with promoters and enhancers and it appears to have a 3' end-forming activity. A lot of long noncoding RNAs tend not to be more than several hundred nucleotides. They're long relative to microRNAs, but they're still quite short relative to a pre-messenger RNA. If you knock out a Pol II elongation factor called SPT6 that is important for transcription initiation across long genes in particular, then the regular protein-coding gene transcripts don't work quite so well, but the antisense long noncoding RNAs start working much better. They not only work much better-you get more of them-but they also go much further. We showed that not having SPT6 causes a loss of recruitment of Integrator, and the phenotype of the cells that don't have SPT6 and therefore make a lot more of these long noncoding RNAs is very bad news. The cell cycle grinds to a halt; the cells go into senescence. We showed that there are lots more R-loops being formed by these extended long noncoding RNAs, and lots of DNA damage.

Richard Sever: Would you expect to see more of these at different times in development? And do you have to have additional mechanisms to cope with this?

Dr. Proudfoot: So far, all of our experiments are based on an easy experimental system, the HeLa cell. HeLa cells are great because they grow really fast, and they're very easy to manipulate. With CRISPR, you can do pretty much anything with the HeLa cell. It grows like a yeast, but it's a mammalian cell type, but of course it's very mutated and very weird. It would be nice to look at these transcript mechanisms in a primary cell or in a stem cell. I would guess in stem cells, where there's a lot more open chromatin, you might expect to see more potential for forming noncoding RNAs. Maybe some of these are more likely to be functional. Those experiments end up being very expensive. You have to make a lot of libraries. We've made probably two or three hundred transcriptomic libraries in the HeLa cell so far, so we know an enormous amount. To get that amount of data in a stem cell would involve a lot of work and we haven't yet embarked on it. I would like to do some of these experiments in primary cells or at least in cells that are slightly less weird. HeLa cells, because they've been cultured for so many generations, have acquired lots of polyploidies in the chromosomal regions. They seem to have evolved in culture to cope with the fact that they're loaded with DNA damage. They have a lot of damage factors up-regulated, which is interesting if you want to study DNA damage, but it basically is aberrant.

Richard Sever: Looking through evolution, different organisms have different amounts of these. Are you looking in other species?

Dr. Proudfoot: In simpler organisms like $S$. cerevisiae, the genome is much smaller so there isn't much space to make a separate transcript between the protein-coding genes, but you can still get antisense transcripts. I also suspect unicellular organisms find it harder to energetically afford to make all these weird transcripts that aren't doing anything, so getting rid of them is probably beneficial. Energy is never a very serious issue for a mammalian cell because in an animal you have homeostasis; you guarantee a concentration of ATP. You can make a whole lot of transcripts that may be beneficial in terms of evolution but are not particularly useful to the animal at that point in time. 


\section{$\$_{\text {CSH\& }}^{\infty}$ Cold Spring Harbor Symposia SYMPOSIA on Quantitative Biology}

\section{A Conversation with Nicholas Proudfoot}

Cold Spring Harb Symp Quant Biol published online March 18, 2020

Access the most recent version at doi:10.1101/sqb.2019.84.039479

$\mathbf{P}<\mathbf{P} \quad$ Published online March 18, 2020 in advance of the print journal.

Creative This article is distributed under the terms of the

Commons http://creativecommons.org/licenses/by/4.0/, which permits unrestricted

License reuse and redistribution provided that the original author and source are credited.

Email Alerting Receive free email alerts when new articles cite this article - sign up in Service the box at the top right corner of the article or click here.

Advance online articles have been peer reviewed and accepted for publication but have not yet appeared in the paper journal (edited, typeset versions may be posted when available prior to final publication). Advance online articles are citable and establish publication priority; they are indexed by PubMed from initial publication. Citations to Advance online articles must include the digital object identifier (DOIs) and date of initial publication.

To subscribe to Cold Spring Harbor Symposia on Quantitative Biology go to: http://symposium.cshlp.org/subscriptions 